\title{
Analysis of longitudinal data of Nellore cattle from performance test at pasture using random regression model
}

\author{
Fernando Brito Lopes ${ }^{1 *}$, Cláudio Ulhôa Magnabosco ${ }^{2}$, Fernanda Paulini ${ }^{3}$, Marcelo Corrêa da Silva ${ }^{4}$, \\ Eliane Sayuri Miyagi ${ }^{4}$ and Raysildo Barbosa Lôbo ${ }^{5}$
}

\begin{abstract}
This study was carried out to estimate (co)variance components and genetic parameters for live weight of Nellore cattle from Performance Test of Young Bulls using random regression models. Data of weights and ages of 925 weaned males was used. The animal model included the fixed effect of contemporary group, age of the animal at weighing as a covariate and as random effects it was considered the effect of additive genetic and permanent environment of the animal. The residue was modeled considering four classes of variances. The models were compared based on the Bayesian information criteria of Akaike and Schwartz. The model polynomial of fourth and sixth order for the direct additive genetic effects and permanent environment of the animal, respectively was the most appropriate to describe the changes in the variances of the weights during the period in which the animals participating in the performance test young bulls. Heritability estimates showed moderate magnitudes and indicated that direct selection will promote improvement of selection criteria adopted. Furthermore, due to high positive correlation between the estimated weights, it was suggested selecting the best animals before at 365 days of age, because it is the period in which the animals have a higher growth rate and thus you can select animals heavier and less delayed.
\end{abstract}

Keywords: Animal breeding, Beef cattle, Heritability, Zebu

\section{Introduction}

The beef cattle production has an important role for the Brazilian agribusiness. This production goes to increase around of $4.4 \%$ until 2015. This is possible due to great potential of Brazilian herd production, which is first in world exports and second largest producer of beef cattle and third in world food consumption (Brasil, 2011).

In Brazil, the Zebu breeds are more than $80 \%$ of national bovine herd. But, these animals have presented difference in growth and production in each Brazilian region due to diversity of climate and management system (Ferraz \& Eler, 2010). Many researchers have studied growth traits as weight in different ages, growth curves and growth rate traits of Nellore cattle in different regions of Brazil (Souza et al., 2008; Lopes et al., 2011;

\footnotetext{
* Correspondence: camult@gmail.com

'Embrapa Cerrado / Capes, Road GO-462, km 12, Rural Area, PO Box 179, CEP: 75375-000, Santo Antônio de Goiás, Brazil

Full list of author information is available at the end of the article
}

Lopes et al., 2012; Santos et al., 2012). However, research that evaluates the growth and development of young bulls in performance test are incipient. Mainly research that use random regression models, which consider all weights of the animals and not just standardized weights to specific ages. (Meyer, 2001; Albuquerque \& Meyer, 2001; Sousa Jr. et al. 2010; Boligon et al., 2010; Baldi et al., 2012; Selapa et al., 2012).

In accordance to Macedo et al. (2009), the covariance functions and random regression models have been considered as an alternative for the adjustment of records obtained in sequence from the same animal along time and which presents a structured pattern of covariance. This occurs due to the fact that phenotypic traits can be measured using same animal for a large number of times. In performance test, many traits are measured for a large number of times. In these tests, the animals have the same average age, are of the same sex, same race, same feed management and are in the same environment and 
Table 1 Summary of the data

\begin{tabular}{ll}
\hline Feature & Number \\
\hline Number of sires & 371 \\
Number of sires with progeny in the data & 245 \\
Number of dams & 478 \\
Number of dams with progeny in the data & 245 \\
Number of animals with records & 925 \\
Number of animals in pedigree & 4,293 \\
Mean age (days) & 409 \\
Starting age range (days) & $209-597$ \\
Contemporary groups & 133 \\
Mean initial body weight $(\mathrm{kg})$ & 147 \\
Mean final body weight $(\mathrm{kg})$ & 506 \\
\hline
\end{tabular}

climate. So, it is possible more easily identify the best animals. Therefore, the essential aim of performance test is to help in the identification of genetically superior animals.

The main objective of breeding programs is the selection of genetically superior animals, based on selection criteria specific to each program. However, the performance of future progeny does not depend solely on parental genotypes, but also the environment and genotype $\times$ environment interaction. Thus, there is no way to remove the influence of environmental on the animal performance. In the performance test the animals should be contemporaneous, created on the same management and feeding. Therefore, there is the effect of genotype $x$ environment interaction and correlation between genetic and phenotypic differences can be maximized.

Thus, this study was carried out to estimate (co)variance components and genetic parameters for live weight of Nellore cattle from Performance Test of Young Bulls using random regression models.

\section{Material and methods}

Data set used in this study was composed by 5,550 records of weight-age of 925 Nellore cattle from Performance Test of Young Bulls, whit general mean and standard-deviation of $294.14 \pm 60.80$. A summary of the data is given in Table 1 . These animals were raised at pasture in Capivara Farm of the Embrapa Rice and Bean during the period of 2001 to 2012.

This farm is located in Santo Antônio de Goiás City, Goiás State, latitude of $16^{\circ} 28^{\prime} 00^{\prime \prime}$, longitude of $49^{\circ} 17^{\prime}$ 00 "W and altitude of $823 \mathrm{~m}$. In accordance with Köppen
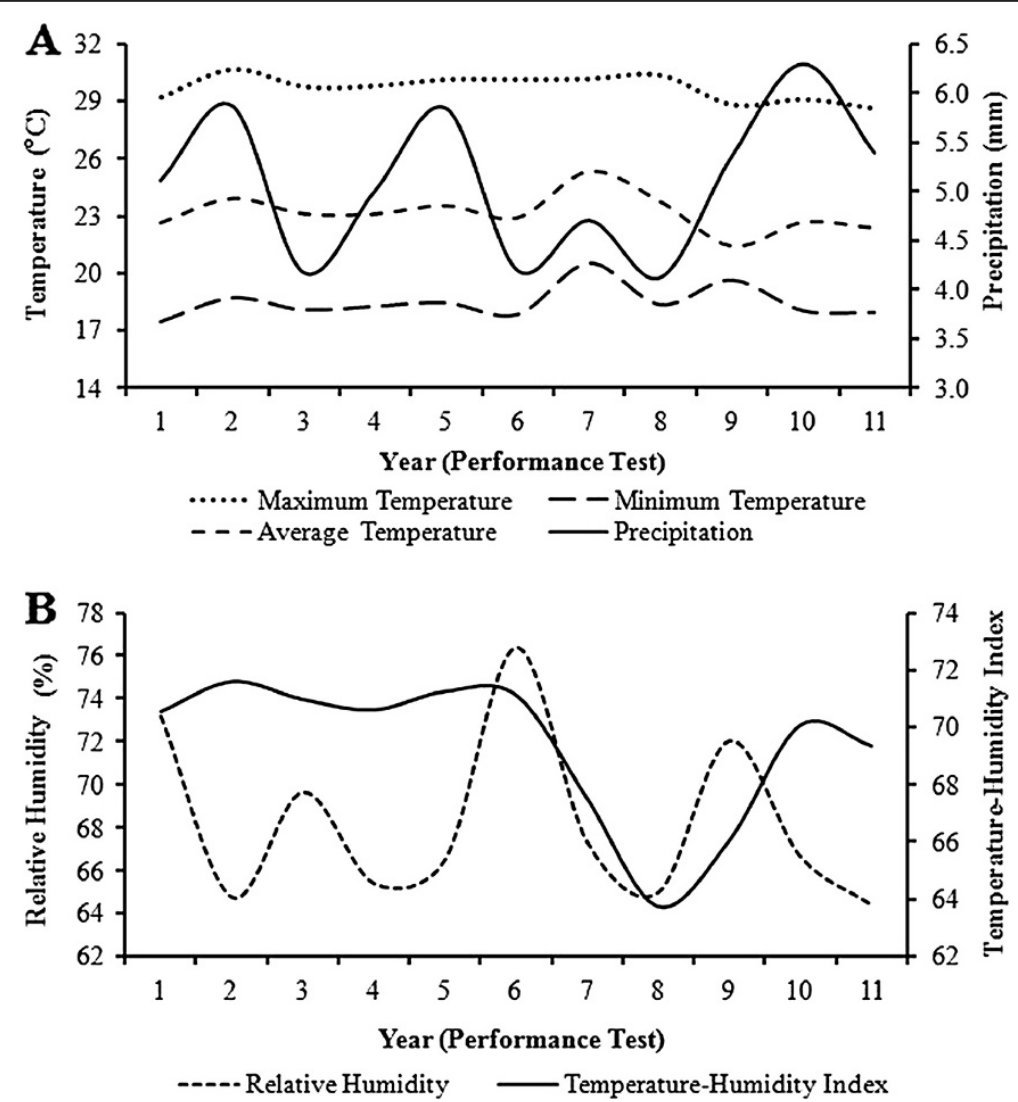

Figure 1 Average, minimum and maximum temperature and precipitation (A) and relative humidity (\%) and temperature and humidity index (B) obtained during the Performance Testing of Young Bulls (TDTJ) raised at pasture. 
this city is classified as Aw climate, savanna tropical and megathermic. The mean air temperature is $23.0^{\circ} \mathrm{C}$ and the minimum and maximum temperature occurs in July and September with average temperature of $14.2^{\circ} \mathrm{C}$ and $31.7^{\circ} \mathrm{C}$, respectively. It present two distinct season, rainy season, between October and April; and dry season, between May and September. The annual average precipitation is $1,485 \mathrm{~mm}$ and the annual average of relative humidity is $71 \%$. The soil is dystrophic red latosol and clayey and your environment is savanna biome and relief plan.

The annual distribution of average, minimum and maximum temperature $\left({ }^{\circ} \mathrm{C}\right)$, precipitation $(\mathrm{mm})$, relative humidity (\%) and temperature humidity index were collected in Climatological Station of Embrapa Rice and Bean, during the years 2001 to 2012 are presented in Figure 1.

In the performance test the animals were fed with $\mathrm{Bra}$ chiaria brizantha, cv Marandu and cv Xaraés, in rotational grazing ( 9 days of occupation by 36 days of rest) defined in accordance with forage offer. It was supplied $7 \mathrm{~kg}$ of forage to each $100 \mathrm{~kg}$ of life weight (LW). Thus, the animals can to select the good forage during the test and were fed with mineral and proteic supplement of minimum consumption during de dry season. Average weight and age at the beginning of the test was $200 \mathrm{~kg}$ and 8 to 10 months, respectively. Animals were weighed regularly during the period of 294 days of performance test.

The animals' weights of performance test were analyzed using random regression models. It was considered as fixed effect the contemporary groups (animals that born in the same year and season and were weighed on the same day) and age of animals as covariate adjusted using Legendre polynomials of third order. As random effects it was considered the direct additive genetic effect and animal environment permanent. This model was:

$$
\begin{aligned}
y_{i j} & =F E+\sum_{m=0}^{k_{b}-1} b_{m} \phi_{m}\left(t_{i}\right)+\sum_{m=0}^{k_{A}-1} \alpha_{j m} \phi_{m}\left(t_{i j}\right) \\
& +\sum_{m=0}^{k_{C}-1} \delta_{j m} \phi_{m}\left(t_{i j}\right)+e_{i j}
\end{aligned}
$$

Where, $y_{i j}$ is the $i^{\text {th }}$ measure of $j^{\text {th }}$ animal; FE is the set fixed effect; $\mathrm{b}_{m}$ is the regression coeficient; $\phi_{m}\left(t_{i}\right)=$ Legendre polynomial regression function; $\phi_{m}\left(t_{i j}\right)=$ Legendre polynomial regression function of each animal $j$ for age,$\left(t_{i}\right)$ in accordance with additive direct genetic effect and animal environment permanent; $\alpha_{j m}$ and $\delta_{j m}=$ random regression coefficients for additive genetic and permanent environment effects, respectively, for each animal; $k_{b}, k_{A}$ and $k_{C}=$ Legendre polynomial order; $e_{i j}=$ random error associated with each age $i$ of animal $j$. The random regression model in its matrix form is:

$$
\mathrm{y}=\mathrm{X} \beta+\mathrm{Z}_{1} \alpha+\mathrm{W}_{1} \delta+\mathrm{e}
$$

Where $\mathrm{E}[\mathrm{y}]=\mathrm{X} \beta, \mathrm{E}[\alpha]=0, \mathrm{E}[\beta]=0$ and $\mathrm{E}[\mathrm{e}]=0$ and (co)variance matrix was:

$$
\operatorname{Var}\left[\begin{array}{l}
\alpha \\
\delta \\
e
\end{array}\right]=\left[\begin{array}{ccc}
K_{A} \otimes A & 0 & 0 \\
0 & K_{C} \otimes I_{N a} & 0 \\
0 & 0 & R
\end{array}\right]
$$

Where, $y$ is the measure vector; $\beta$ is the fixed effects vector (FE and $b_{m}$ ); $\alpha$ is the random coefficients vector of direct addictive genetic effects; $\delta=$ coefficient vector of animal permanent environment; $X, Z_{1}$ and $W_{1}$ is the matrix of fixed effect, direct addictive genetic and animal permanent environment effects, respectively; $K_{A}$ and $K_{C}$ is the (co)variance matrix of direct addictive genetic and animal permanent environment effects, respectively; $A$ is the relationship matrix; $I$ is the identity matrix; $N_{\alpha}=$ number of animals with valid records; $R$ is the residual variance matrix; and $e$ is the error vector.

The Wombat device (Meyer, 2007) was used for the data analysis. Among the many available algorithms of this device, the PX-AI algorithm was chosen, because, it combines the PX (parameter expanded) method, which is a variation of the EM (expectation maximization) algorithm, with the AI (average information) algorithm

\section{Table 2 Order of fit of additive direct $\left(K_{A}\right)$, animal permanent environment effects $\left(K_{C}\right)$, number of parameters (Np), log-likelihood value (log), Akaike information criterion (AIC) and Bayesian information criterion (BIC)}

\begin{tabular}{lllllll}
\hline Model & $\mathbf{K}_{\mathbf{A}}$ & $\mathbf{K}_{\mathbf{C}}$ & Np & log & AIC & BIC \\
\hline M31 & 3 & 1 & 11 & -17502.758 & 17513.758 & 17550.040 \\
M32 & 3 & 2 & 13 & -17500.159 & 17513.159 & 17556.038 \\
M33 & 3 & 3 & 16 & -17481.499 & 17497.499 & 17550.273 \\
M34 & 3 & 4 & 20 & -17440.644 & 17460.644 & 17526.611 \\
M35 & 3 & 5 & 25 & -17412.969 & 17437.969 & 17520.428 \\
M36 & 3 & 6 & 31 & -14666.907 & 14697.907 & 14800.157 \\
M41 & 4 & 1 & 15 & -17467.977 & 17482.977 & 17532.453 \\
M42 & 4 & 2 & 17 & -17464.705 & 17481.705 & 17537.777 \\
M43 & 4 & 3 & 20 & -17449.091 & 17469.091 & 17535.058 \\
M44 & 4 & 4 & 24 & -17436.942 & 17460.942 & 17540.103 \\
M45 & 4 & 5 & 29 & -17410.104 & 17431.104 & 17514.757 \\
M46 & $\mathbf{4}$ & $\mathbf{6}$ & $\mathbf{3 5}$ & $-\mathbf{1 4 2 4 3 . 3 6 1}$ & $\mathbf{1 4 2 7 8 . 3 6 1}$ & $\mathbf{1 4 3 9 3 . 8 0 4}$ \\
M51 & 5 & 1 & 20 & -17444.606 & 17464.606 & 17530.574 \\
M52 & 5 & 2 & 22 & -17441.162 & 17463.162 & 17535.727 \\
M53 & 5 & 3 & 25 & -17424.647 & 17449.647 & 17532.106 \\
M54 & 5 & 4 & 29 & -17417.428 & 17446.428 & 17542.081 \\
M55 & 5 & 5 & 34 & -17408.834 & 17442.834 & 17554.979 \\
M56 & 5 & 6 & 40 & -17405.868 & 17445.868 & 17577.803 \\
\hline & & & & & &
\end{tabular}






(Meyer, 1997). Eighteen models with Legendre orthogonal polynomials of first to sixth order were used to describe the effects of direct additive genetic and animal permanent environment of the animal. It was used four residual variance class in according to the following ranges of age: $209 \leq t \leq 299$ days, $300 \leq t \leq 399$ days, $400 \leq$ $t \leq 499$ days y $500 \leq t \leq 597$ days, where $t$ is the animal age.

Selection of models was based on Akaike's information criterion (Akaike, 1974). Akaike (1974 proposed a simple and useful criterion (AIC) for selecting the best-fit model among alternative models: AIC $=-2 \log$ (maximum likelihood) +2 (number of model parameters). Differences between AIC values are important, not the absolute size of AIC values. The model with the lowest AIC is considered the best. Various experiences verify the applicability of AIC in model selection (Wada \& Kashiwagi, 1990; Burnham \& Anderson, 1998). Another widely used information criterion is the Bayesian Schwarz information criterion (BIC), which takes into account model uncertainty as well Schwarz, (1978). The Bayesian Schwarz information criterion is stricter than the
AIC. The BIC is defined as BIC $=-2 \log$ (maximum likelihood) $-\log (\mathrm{n}) \times$ (number of model parameters), where $\mathrm{n}$ is equal to the number of records used in the analysis (Burnham and Anderson, 1998).

\section{Results and discussion}

In accordance with Akaike and Bayesian information criteria the M46 model showed the best fit (Table 2). The convergence was hampered when there was increase in coefficients of the polynomial, which was also reported by many authors (Meyer, 1999; Arango et al., 2004; Boligon et al., 2010). Dias et al. (2006) showed that while increase the order of polynomials there is also increase on flexibility of curve. However, when higher was order of polynomials higher will be computational resources and worse will be the convergence (Kirkpatrick et al., 1994; Meyer, 1998).

The three main eigenfunctions for additive direct effects obtained with model M46 are shown in Figure 2. Eigenfunctions are continuous functions whose coefficients are formed by the elements of the eigenvectors of the (co)variance matrices. A specific eigenvalue is attributed to each eigenfunction and corresponds to the proportion of total variation that is explained by such eigenfunction. Eigenvalues and eigenfunctions of genetic covariance functions provide an insight into the way selection affects the character under consideration (Kirkpatrick et al., 1990).

The three main eigenvalues of the additive direct (co) variance matrix explained $100 \%$ of total additive variance. The first eigenvalue accounted for $89.82 \%$. The first eigenfunction was negative down of 400 days and positive up to 400 days of age; but the linear trend indicates a positive correlation between weights. Thus, selection for greater weights at any age will increase other weights. There was decrease of second eigenfunction up to 400 days of age and increased thereafter. This change

Table 3 Estimates of variance (diagonal), covariance (below the diagonal) and genetic correlation (above the diagonal) between the random regression coefficients and eigenvalues $(\lambda)$ of the (co)variance matrix for the direct genetic effects and animal permanent environment

\begin{tabular}{|c|c|c|c|c|c|c|c|c|}
\hline Effect & Order of fit & 1 & 2 & 3 & 4 & 5 & 6 & $\lambda$ \\
\hline \multirow[t]{4}{*}{ Additive direct } & 1 & 586.46 & 0.38 & 0.68 & -0.17 & & & 601.14 \\
\hline & 2 & 79.33 & 74.08 & -0.11 & -0.54 & & & 63.89 \\
\hline & 3 & 39.83 & -2.28 & 5.80 & -0.43 & & & 4.23 \\
\hline & 4 & -7.19 & -7.88 & -1.77 & 2.92 & & & 0.00 \\
\hline \multirow[t]{6}{*}{ Animal permanent environment } & 1 & 638.09 & -0.04 & -0.18 & -0.40 & -0.47 & -0.06 & 646.05 \\
\hline & 2 & -9.77 & 108.68 & 0.60 & 0.44 & 0.46 & -0.11 & 159.84 \\
\hline & 3 & -41.38 & 56.28 & 81.85 & 0.88 & 0.76 & 0.07 & 41.08 \\
\hline & 4 & -40.00 & 18.35 & 31.73 & 15.80 & 0.82 & -0.07 & 7.84 \\
\hline & 5 & -29.76 & 11.96 & 17.19 & 8.21 & 6.29 & -0.48 & 1.72 \\
\hline & 6 & -3.59 & -2.84 & 1.55 & -0.70 & -2.90 & 5.82 & 0,00 \\
\hline
\end{tabular}



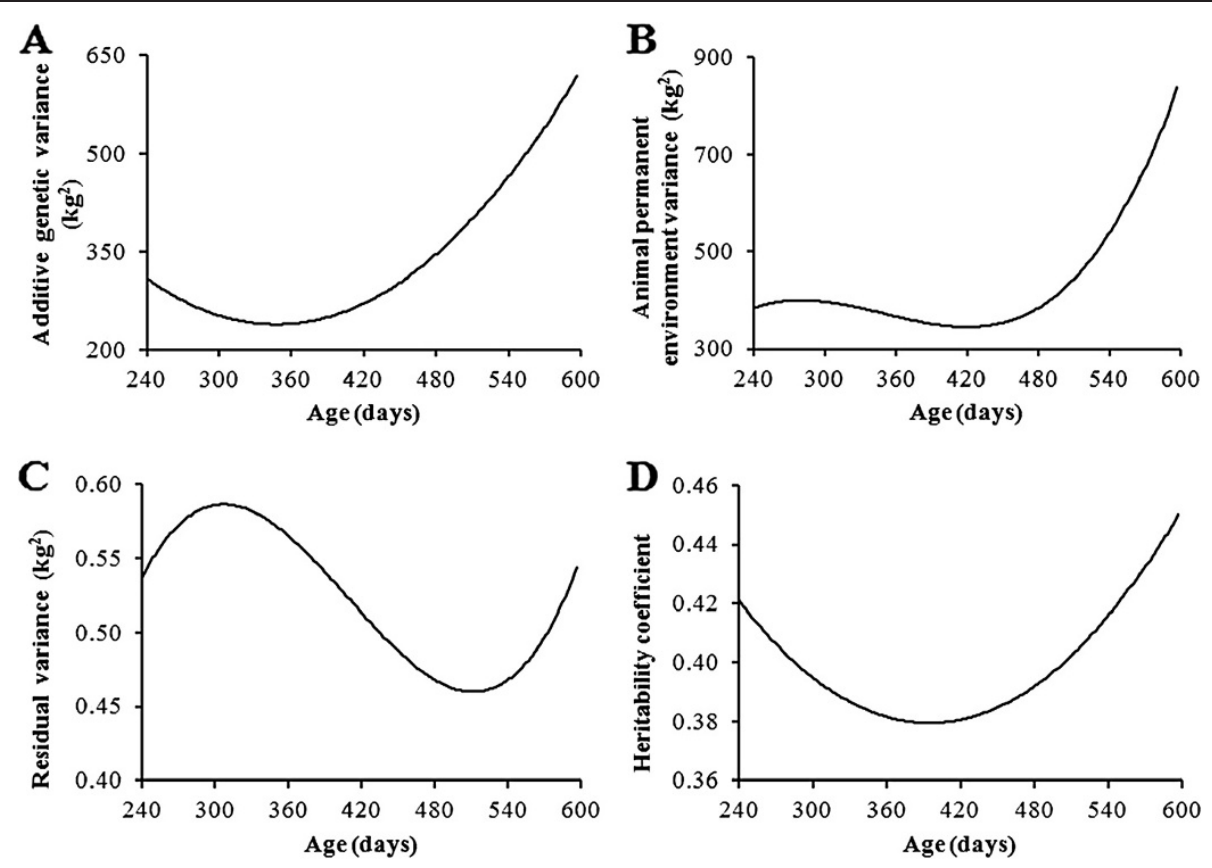

Figure 3 Direct additive genetic variance curves (A), animal permanent environment variance curves (B), residual variance curves (C) and heritability coefficient curves (D) at different ages estimated using M46 models.

indicates that selection for this component will have opposite effects at the beginning and at the end of the trajectory. However, the genetic change due to selection for this component would be small because it was responsible for only $9.55 \%$ of additive variance. Similar results were reported by Albuquerque \& Meyer (2001) for growth from birth to 630 days of age in Nellore cattle.

Estimates of (co)variance between the random regression coefficients for M46 model are showed in Table 3. It was observed that the intercept showed the major variance for the direct addictive genetic effect. The estimates of correlation between the intercept and liner regression coefficient was medium magnitude (0.38), 0.68 between the intercept and quadratic coefficient and -0.17 between the intercept and cubic coefficient. For the animal permanent environment all correlation estimated were negative. Similar results were reported by Meyer (2001), Albuquerque \& Meyer (2001),Sousa Jr. et al. (2010), Boligon et al. (2010) and Baldi et al. (2012).

Table 4 Variance components and heritability coefficients estimates for different ages obtained through the Legendre order four models

\begin{tabular}{lllll}
\hline Age & $\hat{\sigma}_{\boldsymbol{a}}^{2}$ & $\hat{\sigma}_{\boldsymbol{p} \boldsymbol{e}}^{2}$ & $\hat{\sigma}_{\boldsymbol{p}}^{2}$ & $\boldsymbol{h}^{\mathbf{2}}$ \\
\hline 240 & 313.98 & 392.62 & 727.16 & 0.43 \\
365 & 232.00 & 355.60 & 627.58 & 0.37 \\
450 & 308.48 & 407.14 & 803.66 & 0.38 \\
550 & 495.28 & 465.93 & 1073.13 & 0.46 \\
\hline
\end{tabular}

$\hat{\sigma}_{a} 2$ : additive direct genetic variance; $\hat{\sigma}_{p e} 2$ : animal permanent environment effect variance; $\hat{\sigma}_{p} 2$ : phenotypic variance; $\mathrm{h}^{2}$ : heritability for direct effect.
The variance components and heritability coeficients estimated for animals weight are show in the Figure 3. There was decrease in adictive genetic variance between 240 and $360 \mathrm{~d}$, after this period there was increase of theses estimatives, corroborating the results of Boligon et al. (2010), Sousa Jr. et al., (2010). There was small variability in the variance componente of animal permanent environment between 240 days and 450 days of age. After 450 days there was high increase in this componente. In general, these results were corroborated by several authors (Albuquerque \& Meyer, 2001; Nobre et al., 2003; Dias et al., 2006, Baldi et al., 2012; Selapa et al., 2012).

There was quadratic trend for heritability estimates with major values at beginning and end of performance test. The estimatives of heritability ranged from 0.35 to 0.46. Similar results were reported by Souza et al. (2008) which showed heritabilities of 0.15 until 0.45 between birth and 660 days of age. Boligon et al. (2010) showed

Table 5 Components of genetic covariance (below diagonal) and genetic correlation coefficients (above diagonal) estimates for different ages obtained through the Legendre order four models

\begin{tabular}{lllll}
\hline Age & $\mathbf{2 4 0}$ & $\mathbf{3 6 5}$ & $\mathbf{4 5 0}$ & $\mathbf{5 5 0}$ \\
\hline 240 & & 0.90 & 0.75 & 0.75 \\
365 & 241.72 & & 0.95 & 0.90 \\
450 & 233.06 & 252.91 & & 0.99 \\
550 & 233.06 & 304.34 & 387.87 & \\
\hline
\end{tabular}


range of heritability of 0.34 to 0.42 between birth and 550 days of age.

Estimative of variance components and heritability coefficients for weight at 240, 365, 450 and 550 days of age are showed in Table 4. It was observed major values of variances components and heritabilities at 240 and 550 days of age. The direct genetic correlation estimates between weights from 240 to 550 are shown in Table 5 . The genetic correlation estimates decreased when distance between records increased.

The genetic correlations were greater than 0.70 at most ages. Similar estimates, varying from 0.43 to 0.88 , were described by Boligon et al. (2009). These results suggest that selection for greater weight at any age should increase mature weights (Boligon et al., 2010). The later the selection is performed, the greater the response in mature weight. Selection is performed using weight from weaning to 550 days of age, mainly. This might increase the adult size of animals, which is not always desired (Dias et al., 2006; Boligon et al., 2008). Arango et al. (2004) also reported strong genetic correlations between weight from 840 to 2,160 days of age (close to 0.84) and between 2,160 and 3,090 days of age (close to 0.90). Due to high genetic correlation estimated between these weights we suggested the selection of young animals, but those that had a higher growth rate, thus avoiding the selection of animal very heavy and late growth.

\section{Conclusions}

The model that polynomials of fourth and sixth order for the direct additive genetic and animal permanent environment effects, respectively, were the most appropriate to describe the changes in the variances of the weights during the period in which the animals participating in the performance test young bulls.

Heritability estimates showed moderate magnitudes and indicated that direct selection will promote improvements in the selection criteria adopted. Furthermore, due to the high positive genetic correlation, we suggest selecting the best animals in the previous 365 days of age, because this is the period in which the animals have a higher growth rate and thus it can select precocious and heavier animals.

\section{Competing interests}

The authors declare that they have no competing interests.

\section{Authors' contribution}

FBL,CUM, FP, MCS, ESM and RBL carried out the molecular genetic studies and all authors participated in the sequence alignment and drafted the manuscript, read and approved the final manuscript.

\section{Acknowledgment}

The authors are indebted to ANCP (Brazilian Society of Breeders and Researchers) for providing genealogical data.

\section{Author details}

'Embrapa Cerrado / Capes, Road GO-462, km 12, Rural Area, PO Box 179, CEP: 75375-000, Santo Antônio de Goiás, Brazil. 'Embrapa Cerrado/CNPq, Brasília, DF, Brazil. ${ }^{3}$ Program in Animal Biology, Universidade de Brasília, Brasília, DF, Brazil. ${ }^{4}$ Program in Animal Science, Federal University of Goiás, Goiânia, GO, Brazil. ${ }^{5}$ Brazilian Society of Breeders and Researchers, Ribeirão Preto, São Paulo, Brazil.

Received: 15 October 2012 Accepted: 16 November 2012

Published: 20 November 2012

\section{References}

Akaike H (1974) A new look at the statistical model identification. IEEE Trans Autom Control 19:716-723

Albuquerque LG, Meyer K (2001) Estimates of covariance functions for growth from birth to 630 days of age in Nelore cattle. J Anim Sci 79:2776-2789

Arango JA, Cundiff LV, Van Vleck L (2004) Covariance functions and random regression models for cow weight in beef cattle. J Anim Sci 82:54-67

Baldi F, Albuquerque LG, Cyrillo JNDG, Branco RH, Oliveira BC, Mercadante MEZ (2012) Genetic parameter estimates for live weight and daily live weight gain obtained for Nellore bulls in a test station using different models. Livest Sci 144:148-156

Boligon AA, Albuquerque LG, Rorato PRN (2008) Associações genéticas entre pesos e características reprodutivas em rebanhos da raça Nelore. Revista Brasileira de Zootecnia 37:596-601

Boligon AA, Albuquerque LG, Mercadante MEZ, Lobo RB, (2009) Herdabilidades e correlações entre pesos do nascimento ã idade adulta em rebanhos da raça Nelore. Revista Brasileira de Zootecnia 38:2320-2326

Boligon AA, Mercadante MEZ, Forni S, Lobo RB, Albuquerque LG (2010) Covariance functions for body weight from birth to maturity in Nellore cows. J Anim Sci 88:849-859

Brasil - Ministério da Agricultura, Pecuária e Abastecimento (2011) Projeções do agronegócio: mundial e brasileiro. http://www.agricultura.gov.br

Burnham KP, Anderson DR (1998) Model Selection and Inference: a Practical Information-theoretic Approach. SpringerVerlag, New York

Dias LT, Albuquerque LG, Tonhati H, Teixeira RA (2006) Estimação de parâmetros genéticos para peso do nascimento aos 550 dias de idade para animais da raça Tabapuã utilizando modelos de regressão aleatória. Revista Brasileira de Zootecnia 35:1915-1935

Ferraz JBS, Eler JP (2010) Parceria público x privada no desenvolvimento de pesquisa em melhoramento genético animal. Revista Brasileira de Zootecnia 39:216-222

Kirkpatrick M, Lofsvold, D, Bulmer M 1990 Analysis of the inheritance, selection and evolution of growth trajectories. Genetics 124:979-993

Kirkpatrick M, Hill WG, Thompson R (1994) Estimating the covariance structure of traits during growth and aging, illustrated with lactations in dairy cattle. Genet Res 64:57-69

Lopes FB, Silva MC, Marques EG, Ferreira UL (2011) Ajustes de curvas de crescimento em bovinos Nelore da região Norte do Brasil. Revista Brasileira de Saúde e Produção Animal, Salvador 12:607-617

Lopes FB, Santos GCJ, Silva MC, Marques EG, Ferreira JL (2012) Tendência genética para características relacionadas a velocidade de crescimento em bovinos Nelore da região Norte do Brasil. Revista Ciência Agronômica 43:362-367

Macedo OJ, Barbin D, Mourão GB (2009) Genetic parameters for post weaning growth of Nellore cattle using polynomials and trigonometric functions in random regression models. Sci Agric 66:522-528

Meyer K (1997) An 'average information' restricted maximum likelihood algorithm for estimating reduced rank genetic matrices or covariance functions for animal models with equal design matrices. Genet Selection Evolution 29:97-116

Meyer K (1998) Estimating covariances functions for longitudinal data using a random regression model. Genet Selection Evolution 30:221-240

Meyer K (1999) Estimates of genetic and phenotypic covariance functions for post weaning growth and mature weight of beef cows. J Anim Breed Genet 116:181-205

Meyer K (2001) Estimates of genetic covariance functions assuming a parametric correlation structure for environmental effects. Genetic Selection Evolution 33:557-585

Meyer K (2007) WOMBAT - A program for mixed models analyses in quantitative genetics by REML. J Zhejiang Uni SCIENCE B 8:815-821 
Nobre PRC, Misztal I, Tsuruta S, Bertrand JK, Silva LOC, Lopes PS (2003) Analysis of growth curves of Nellore cattle by multiple-trait and random regression models. J Anim Sci 81:918-926

Santos GCJ, Lopes FB, Marques EG, Silva MC, Cavalcante TV, Ferreira JL (2012) Tendência genética para pesos padronizados aos 205, 365 e 550 dias de idade de bovinos nelore da região Norte do Brasil. Acta Scientiarum Animal Sciences 34:97-101

Selapa NW, Nephawe KA, Maiwashe A, Norris D (2012) Genetic analysis of body weights of individually fed beef bulls in South Africa using random regression models. Genet Mol Res 11:271-276

Souza JC, Silva C, Simões GH, Moser T, Ostapenchen J, Nicolau Pinto PH, Malhado M, Ferraz Filho PB, Freitas JA, Sereno JRB (2008) Tendências ambientais e genéticas para características produtivas de bovinos da raça Nelore. Arch Latinoam Prod Anim 16:85-90

Sousa SC Jr, Oliveira SMP, Albuquerque LG, Boligon AA, Filho RM (2010) Estimação de funções de covariância para características de crescimento da raça Tabapuã utilizando modelos de regressão aleatória. Revista Brasileira de Zootecnia 39:1037-1045

Schwarz G (1978) Estimating the dimension of a model. Ann Stat 6:461-464

Wada Y, Kashiwagi N (1990) Selecting statistical models with information statistics. J Dairy Sci 73:3575-3582

doi:10.1186/2193-1801-1-49

Cite this article as: Lopes et al:: Analysis of longitudinal data of Nellore cattle from performance test at pasture using random regression model. SpringerPlus 2012 1:49.

\section{Submit your manuscript to a SpringerOpen ${ }^{\circ}$ journal and benefit from:}

- Convenient online submission

- Rigorous peer review

- Immediate publication on acceptance

- Open access: articles freely available online

- High visibility within the field

- Retaining the copyright to your article

Submit your next manuscript at $\boldsymbol{~ s p r i n g e r o p e n . c o m ~}$ 